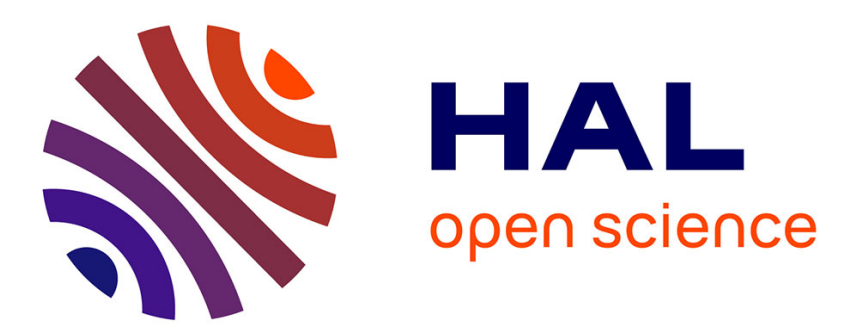

\title{
Functional collembolan assemblages induce different plant responses in Lolium perenne
}

Bruna R Winck, Matthieu Chauvat, Sékou Coulibaly, Mathieu Santonja, Enilson Luiz Saccol de Sá, Estelle Forey

\section{- To cite this version:}

Bruna R Winck, Matthieu Chauvat, Sékou Coulibaly, Mathieu Santonja, Enilson Luiz Saccol de Sá, et al.. Functional collembolan assemblages induce different plant responses in Lolium perenne. Plant and Soil, 2020, 452 (1-2), pp.347-358. 10.1007/s11104-020-04579-0 . hal-02746504

\section{HAL Id: hal-02746504 https://hal-amu.archives-ouvertes.fr/hal-02746504}

Submitted on 15 Sep 2020

HAL is a multi-disciplinary open access archive for the deposit and dissemination of scientific research documents, whether they are published or not. The documents may come from teaching and research institutions in France or abroad, or from public or private research centers.
L'archive ouverte pluridisciplinaire HAL, est destinée au dépôt et à la diffusion de documents scientifiques de niveau recherche, publiés ou non, émanant des établissements d'enseignement et de recherche français ou étrangers, des laboratoires publics ou privés. 
1 Functional collembolan assemblages induce different plant responses in Lolium perenne

2

3 Bruna R. Winck ${ }^{1^{*+}}$, Matthieu Chauvat ${ }^{2{ }^{*}}$, Sekou F.M. Coulibaly ${ }^{2 *}$, Mathieu Santonja ${ }^{3}$, Enilson Luiz Saccol

4 de Sá $^{4}$, Estelle Forey ${ }^{2 *}$

5

$6{ }^{1}$ Department of Ecology, Federal University of Rio Grande do Sul-UFRGS, 91501-970, Porto Alegre - RS,

7 Brazil. ${ }^{(+)}$Email: bru.winck@gmail.com

8

$9{ }^{2}$ Normandie Université, UNIROUEN, IRSTEA, ECODIV, FED SCALE CNRS 3730, France. ${ }^{(+)}$Email: 10 matthieu.chauvat@univ-rouen.fr.

${ }^{3}$ Aix Marseille Univ, Avignon Université, CNRS, IRD, IMBE, Marseille, France

13

$14{ }^{4}$ Department of Soil Science, Federal University of Rio Grande do Sul-UFRGS, 91540-000, Porto Alegre $15-\mathrm{RS}$, Brazil

16

17

*These authors contributed equally to the work

18

19

\section{Acknowledgments}

20

21

BR Winck was granted by Coordenação de Aperfeiçoamento de Pessoal de Nível Superior 22 (CAPES), Brazil. SFM Coulibaly was granted by Région "Haute-Normandie" through the GRR 23 TERA-SCALE 2016. We thank all members of the Ecodiv lab for technical assistance and fruitful 24 discussions.

25 


\section{Abstract}

28 Background and aims

29 Interactions between functional groups of soil fauna and plants are poorly explored although they drive

30 functional processes such as nutrient availability and therefore plant performance. Here, we investigated

31 the separated and combined effects of two collembolan functional groups on soil properties and growth of

32 Lolium perenne, a typical grass species from temperate grasslands.

33

34 Methods

35 Under microcosm conditions, we established four treatments based on the presence and combination of two 36 collembolan functional groups: 1) control without Collembola; 2) epedaphic species; 3) euedaphic species;

37 4) epedaphic+euedaphic species. After five months of experiment, we measured the effect of those 38 treatments on both nutritional and morphological variables of L. perenne and on soil properties.

40 Results

41 Collembolan presence stimulated plant performance. Individuals of $L$. perenne growing with euedaphic 42 species presented higher numbers of leaves and nutrient contents compared with individuals growing with 43 epedaphic species. Further, the combination of both collembolan functional groups enhanced plant 44 performance and soil nutrient availability, demonstrating that a functionally diversified soil fauna assemblage cause overyielding of ecological processes.

Conclusion

48 Our results provide evidences of complementarity interactions between different functional groups of soil 49 fauna causing overyielding of primary production.

52 Functional complementarity; facilitation, plant performance; springtails; soil fauna; biotic interaction

\section{Introduction}

It is acknowledged that soil decomposers at the basis of "brown food webs" play an important role 57 in regulating different ecosystem functionalities, i.e. organic matter decomposition, nutrient cycling, carbon 58 storage, and net primary production (Eisenhauer et al. 2018). Although soil microbes have a direct effect on nutrient mineralization by degrading complex organic compounds such as cellulose and lignin, their composition, structure and activity are often influenced by the presence of animal decomposers such as

61 Collembola and earthworms (Cragg and Bardgett 2001; Ngosong et al. 2004; Eisenhauer et al. 2010; 62 Coulibaly et al. 2019). By feeding on organic residues at different decomposition stages (Endlweber et al. 63 2009; Chahartaghi et al. 2005) and/or a wide range of soil microbes (Tordoff et al. 2008; Lenoir et al. 2006), 64 soil animal decomposer activity may translate to plant performance by influencing the rates of 
mineralization and nutrient availability for plants (Scheu et al. 1999; Bardgett and Chan 1999; Partsch et al. 2006; Hedde et al. 2010; Eisenhauer et al. 2011, 2018; Forey et al. 2015).

Results of several experiments have reported that plants growing with decomposers present higher shoot biomass and foliar nutrient content due to the enhanced soil fertility and nutrient uptake (Partsch et al. 2006; Schütz et al. 2008; Wagg et al. 2014; Forey et al. 2015). In parallel, complementary works reported that the level of diversity and functional dissimilarity within a given assemblage of soil animal decomposers might determine the magnitude of ecological processes (Heemsbergen et al. 2004; Eisenhauer et al. 2011).

72 For instance, Partsch et al. (2006) noticed that root biomass decreased in the presence of either Collembola 73 or earthworms but increased when both organisms were present. Likewise, using three different collembolan species (each of them belonging to a different functional group), Eisenhauer et al. (2011) observed that shoot and root biomasses were significantly higher in forb communities containing three collembolan species than in those containing one or two species. In this last case, despite the authors were not able to decipher the effect of species identity from the effect of functional group, they suggested that the positive effect of collembolan richness on plant growth was due to complementary interaction among the three species or functional groups. Complementarity occurs when the presence of some species improve resource availability or environmental conditions for other species, also called facilitation (Schmid et al. 2008; Hedde et al. 2010; Guenay et al. 2013), or when species share resources, resulting in niche partitioning (Finke and Snyder 2008; Hooper et al. 2005; Brady et al. 2002). Therefore, complementarity is thought to be the primary mechanism that may account for positive patterns through greater efficiency in resource use, leading to the phenomenon of overyielding (Hector et al. 2002; Loreau et al. 2002), that represents an increase of ecosystem productivity (Isbell et al., 2015; Clark et al., 2012; Díaz and Cabido, 2001; Loreau and Hector, 2001). Overyielding has been widely demonstrated within plant communities through manipulation of their diversity in experiments focusing on plant productivity (Schmid et al. 2008; Gross et al. 2007; Hector et al. 2002) or litter decomposition efficiency (Gartner and Cardon 2004; Santonja et al. 2015). But, to our knowledge, the effects of different functional groups of soil organisms alone or in combination upon soil functioning and plant growth are still largely unexplored. This is especially true regarding the community effects, as most of the studies previously described were done at the species level (i.e. one species per functional group). By focusing on soil Collembola, one of the major decomposer groups in the soil, strongly interacting with the microbial component (Coulibaly et al. 2019), we wanted to

94 address this gap of knowledge by using a natural community approach (i.e. working with natural assemblages of several species).

Collembolan species are differentiated according to their vertical distribution, food preference and bio-demographic strategies (i.e. r or K strategy) (Chauvat et al. 2014; Chahartaghi et al. 2005; Petersen 2002; Hopkin 1997), which enable different functional roles in the ecosystem. Epedaphic species are surface dweller dominated by strongly pigmented species with large body size and biomass, well-developed eyes and appendages (i.e. furca, antennae, legs). They have a high metabolic activity and consume highly palatable food substrates like pollen or algae (Petersen 2002). According to Rusek (1998), epedaphic species tend to stimulate microbial colonization of fresh litter, speeding up decomposition rates, but with the risk of nutrients immobilization in the microbial loop. Furthermore, Coulibaly et al. (2019) showed that

104 epedaphic Collembola mainly relates to Gram-positive bacteria. In contrast, the euedaphic group is 
dominated by species with small body size and biomass, colorless and with reduced appendages. Those are deep-living species that consume low-quality food and have a low metabolic activity. Unlike epedaphic species, several euedaphic species were shown to increase mineralization processes into the soil and to affect root nutrient uptake by regulating microbial activity within the rhizosphere (Petersen, 2002). They rather stimulate Gram-negative bacteria (Coulibaly et al. 2019). Finally, the hemiedaphic group includes species sharing intermediate characteristics. In this work, we aim to evaluate the effects of natural assemblages of epedaphic and euedaphic Collembola, alone or in combination, on plant and soil compartments. We addressed the following hypotheses: i) collembolan presence stimulates plant

113 performance through an increase in nutrient mineralization and nutrient availability; ii) euedaphic

114 Collembola have a more positive effect on plants compared with the epedaphic group because they are 115 directly linked to increases in soil nutrient mineralization by stimulating microbial activity in the 116 rhizosphere; iii) complementarity interaction through niche partitioning takes place between epedaphic and 117 euedaphic Collembola due to their functional dissimilarity, resulting in a higher plant productivity (i.e. 118 overyielding).

\section{Material and methods}

Experimental set-up

The experiment was carried out under microcosm conditions using soil and Collembola collected

124 at a depth of 0-10 cm from a native grassland site located on Yvetot (49 $\left.37^{\prime} 04.00^{\prime \prime} \mathrm{N}, 0^{\circ} 45^{\prime} 18.76^{\prime \prime} \mathrm{E}\right)$,

125 Lycée Agricole d'Enseignement Général et Technique Agricole d'Yvetot (Seine-Maritime, Haute-

126 Normandie), France. The soil was classified as Neoluvisol-Luvisol (French Classification; INRA 1998),

127 characterized by a $\mathrm{pH}$ water of 6.1 and a particle-size distribution of $200 \mathrm{~g}$ sand, $650 \mathrm{~g}$ silt and $150 \mathrm{~g}$ clay

128 per kg.

The microcosms were constructed by filling plastic flowerpots of $250 \mathrm{~mL}$ with $150 \mathrm{~g}$ of substrate that consisted of a mixture of defaunated soil (sieved through a $5 \mathrm{~mm}$ mesh) with one centimeter of sand at the bottom for drainage. The soil was defaunated by autoclaving (twice at $105^{\circ} \mathrm{C}$ for 15 min every $48 \mathrm{~h}$ ). After the autoclaving, the soil was dried at $105^{\circ} \mathrm{C}$, sieved at $2 \mathrm{~mm}$ and then placed above the sand.

We used a microbial suspension (fresh soil + physiological solution $-0.85 \% \mathrm{NaCl}$ in the proportion of 4:1) to adjust all microcosms to $70 \%$ water holding capacity and to re-establish the microbial community. Fifteen days after microbial inoculation, a single seedling of Lolium perenne (L.), a typical and dominant forage grass species from temperate grasslands, was transplanted into each microcosm and then we inoculated Collembola.

In this study, we focused our attention on two highly contrasted Collembola functional groups: epedaphic (Ep) and euedaphic (Eu) species. Collembolan communities of each functional group were taken from soil monoliths which were extracted using a Berlese-Tullgren funnel during 7 days. Epedaphic species were extracted from litter layer and soil surface ( 0 to $1 \mathrm{~cm}$ depth) and euedaphic species were obtained

142 from soil subsurface (4 to $6 \mathrm{~cm}$ depth). To collect living collembola, we used the same protocol as described 143 in Coulibaly et al. (2019). We placed pots filled with moist plaster under the funnels. Once extracted, 144 inoculation of Collembola into the microcosms to establish the different treatments was done with help of 
145 homemade pooters. To control inoculation of the right functional group (epedaphic or euedaphic) into the

146 right treatment, Collembola were sorted out under binocular before being transferred with the pooters.

147 Under the binocular, we used three morphological criteria to distinguish the two functional groups, namely

148 pigmentation, ocelli, and jump organ: the furca. Individuals were considered as euedaphic if they were not

149 pigmented, had no ocelli and no furca observable at the binocular. Individuals strongly pigmented, with a

150 large patch of ocelli and a long furca were categorized into epedaphic species. Individuals that did not share

151 these criteria were left out. Based on this protocol, we worked at community level since we extracted an

152 entire community from soil for each group and we established four treatments: C (control without

153 Collembola); Ep (only epedaphic species); Eu (only euedaphic species); and Ep + Eu (both collembolan

154 functional groups). Fifteen replicates per treatment were considered for a total of 60 microcosms. For more

155 details, see Coulibaly et al. (2019). Empty cylinders of $6 \mathrm{~cm}$ diameter and of $6 \mathrm{~cm}$ height that fitted on top

156 of the soil (one cylinder per microcosm) were used to avoid escape of collembolan species.

157 Before beginning of the experiment, collembolan assemblages were characterized in each

158 treatment (Supplementary Table S1). Dominant species in the epedaphic community were Isotomorus

159 prasinus, Lepidocyrtus cyaneus and Desoria violacea. The euedaphic community was mainly composed

160 by Isotomiella minor, Cryptopygus sp., Mesophorura yosii, and Protaphorura armata.

161 After collembolan inoculation, microcosms were incubated during 5 months in climate-controlled

162 chambers with a constant $20^{\circ} \mathrm{C}$ temperature, a $16 \mathrm{~h}: 8 \mathrm{~h}$ light: dark photoperiod, and a light intensity of

1635000 lux. Microcosms were watered with demineralized water every 3rd day to compensate for

164 evapotranspiration and soil moisture was adjusted by weighing the microcosms. At the end of the

165 experiment, functional assemblages of collembolan communities were maintained (Supplementary Table

$166 \mathrm{~S} 1)$.

\section{Measurement of ecological processes}

169 Collectively, all variables related to plant and soil were interpreted as measurements of ecological

170 processes such as organic matter decomposition, nutrient mineralization, soil nutrient turnover and

171 consequently plant growth and primary production.

172 At the end of the experiment (5 months), shoot traits were measured on all plant individuals. The

173 total numbers of replicates per treatment changed during the experiment, since some plant individuals were

174 lost. Thus, the number of replicates (n) per treatment was: Control $(n=13), E p(n=11), E u(n=11)$, and

$175 \mathrm{Ep}+\mathrm{Eu}(\mathrm{n}=12)$. Root traits were only measured on five randomly selected individuals per treatment $(\mathrm{n}=$

176 5) in order to leave intact soil replicates for further soil measurements. Number of leaves and maximum

177 height were determined before harvest on all L. perenne individuals. Subsequently, plants were harvested

178 and carefully washed to measure different morphological and chemical variables. Shoot was cut at the soil

179 surface and was dried at $65^{\circ} \mathrm{C}$ for $48 \mathrm{~h}$ to obtain shoot dry biomass. Fresh root volume was measured using

180 a graduated cylinder and then roots were dried at $65^{\circ} \mathrm{C}$ for $48 \mathrm{~h}$ to obtain root dry biomass. Each shoot

181 sample was powdered in order to measure carbon $(\mathrm{C})$ and nitrogen $(\mathrm{N})$ content by gas chromatography

182 using a CHN pyrolysis micro-analyzer (Flash 2000 Series, CHNS/O Analyser Thermo Scientific, France)

183 and phosphorus (P) and sulphur (S) content using an atomic absorption spectrophotometer (AAS, ICE 3000

184 SERIES, Thermo Scientific, China). 
Soil chemical variables were quantified on six randomly selected samples per treatment $(n=6)$. The soil was sieved through a $2 \mathrm{~mm}$ mesh to remove large roots and stored at $4{ }^{\circ} \mathrm{C}$ until further processing.

187 Dissolved organic carbon and mineral nitrogen $\left(\mathrm{N}^{-\mathrm{NO}_{3}}{ }^{-}\right.$and N-NH$\left.{ }^{+}\right)$were extracted using $0.25 \mathrm{M} \mathrm{K}_{2} \mathrm{SO}_{4}$.

188 For that, $20 \mathrm{~g}$ of sieved soil $(2 \mathrm{~mm})$ were shaken for $1 \mathrm{~h}$ in a solution of a $0.25 \mathrm{M} \mathrm{K}_{2} \mathrm{SO}_{4}$, and then filtered

189 through a Whatman 42 filter. Concentrations of dissolved organic carbon were measured by gas

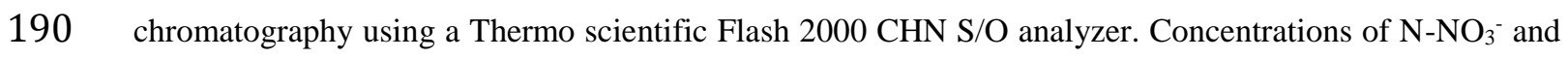

$191 \mathrm{~N}^{-\mathrm{NH}_{4}}{ }^{+}$were determined colorimetrically (Sequential analyser Gallery, Thermo scientific).

$192 \quad \mathrm{~A} \mathrm{HCl}-\mathrm{HNO}_{3}$ digestion procedure followed by an analysis of the digested solution using atomic

193 absorption spectrophotometry (AAS, ICE 3000 SERIES, Thermo Scientific, China) was employed to

194 determine total phosphorus $(\mathrm{P})$ and sulfur $(\mathrm{S})$ concentrations in soil samples. Soil $\mathrm{pH}$ in water $\left(\mathrm{pH}_{\mathrm{H} 2 \mathrm{O}}\right)$ was

195 determined following ISO 10390.

196

Data analyses

The effects of collembolan treatments on plant and soil variables were evaluated by analysis of variance (ANOVA) with permutation tests. $P$-values were determined using 10,000 permutations (Anderson 2001). Tests were chosen since data are non-parametric and do not assume normally distributed errors. Post-hoc t-statistic tests are used to allow pairwise comparisons between all pairs of treatments (Anderson, 2001). To explore the interaction between Ep and Eu treatments, we first performed two-way ANOVAs with epedaphic or euedaphic Collembola as two independent factors. Then, to identify if complementarity interaction occurs between Ep and Eu on ecological processes, we firstly calculated a Relative Effect Index (REI) on the different measured soil and plant variables: $R E I=\left(\mathrm{X}_{\mathrm{T}}-\mathrm{X}_{\mathrm{C}}\right) / \mathrm{X}_{\mathrm{C}}$, where $\mathrm{X}_{\mathrm{T}}$ corresponds to the value of a treatment including collembolan species (i.e. Ep, Eu, or Ep+Eu treatments), and $\mathrm{X}_{\mathrm{C}}$ corresponds to the mean value of the control treatment (i.e. without Collembola). Then, we compared the REI values observed in the treatment including the two collembolan functional groups (i.e. $\mathrm{Ep}+\mathrm{Eu}$ ) with expected values based on the two treatments Ep and Eu. This Combined Functional Group Effect (CFGE) was calculated according to the formula: Observed REI - Expected REI, where the Observed REI value corresponds to the REI of the combined treatment $(\mathrm{Ep}+\mathrm{Eu})$, while Expected REI corresponds to the additive value of REI for Ep and Eu. This CFGE could be additive (no significant difference between observed and expected values), synergistic (higher observed than expected values) causing overyielding, or antagonistic (lower observed than expected values) causing underyielding effects on plant and soil properties. Based on literature, additive effects will indicate niche partitioning, most probably for spatial resources; positive effects indicate facilitative interactions for resource use, while negative effects will indicate competitive interactions for resource use (Loreau and Hector 2001; Hedde et al. 2010). We performed two sample-paired tests ( $t$ test) to compare expected REI (sum of single functional groups) and observed REI (Ep+Eu) for each response variable of soil and plant. All statistical analyses and permutation tests were performed using the statistical software PAST v.3.25, available at https://folk.uio.no/ohammer/past/ (Hammer et al. 2001). 
The presence of Collembola led to significant changes for five out of six measured soil variables (Table 1). All nutrients were more concentrated in Ep+Eu than in control treatment. The Eu treatment had intermediate values for $\mathrm{P}$ and $\mathrm{S}$, and lower values than $\mathrm{Ep}+\mathrm{Eu}$ treatment for both $\mathrm{NO}_{3}{ }^{-}$and $\mathrm{NH}_{4}{ }^{+}$. The Ep treatment was similar to the control for $\mathrm{NO}_{3}{ }^{-}, \mathrm{NH}_{4}{ }^{+}$and $\mathrm{P}$. The $\mathrm{pH}$ showed a different pattern, being higher in control than in Ep with the two other treatments having intermediate values. Finally, for all soil variables, no significant difference was detected between Ep and Eu treatments.

\section{Nutritional plant performance}

Foliar nutrient contents of $L$. perenne were strongly affected by collembolan presence, whatever the assemblages (Table 2; Fig. 1A). Comparatively to the control, foliar C content was significantly lower in Ep+Eu treatment (-4.8\%). Maximum foliar $\mathrm{C}$ was observed for the Eu treatment. Nitrogen and S showed an increased concentration when increasing the complexity of collembolan assemblage (control $<\mathrm{Ep}$ or Eu $<\mathrm{Ep}+\mathrm{Eu})$. Indeed, the presence of Ep, Eu and Ep+Ep species increased respectively by 36\%, 32\% and 67\% the $\mathrm{N}$ content in leaves compared with the control treatment. Foliar S content was around 2.2-fold higher in Ep+Eu than in control treatment. Similarly, C:N and C:S ratios were 1.7 and 2.4-fold lower in Ep+Eu than in control treatment, respectively. Only $\mathrm{C}$ and $\mathrm{S}$ content in leaves were different between the treatments with a single collembolan functional group, with higher values in Eu than in Ep treatments.

Foliar P content was higher in the presence of Collembola than in their absence, and this whatever the treatment. Similarly, the C:P ratio was higher in presence than in absence of Collembola.

\section{Plant performance}

Except for plant height, all other morphological traits were affected by collembolan treatments (Fig.1). Overall, plants growing with Eu and Ep+Eu had $47 \%$ and $68 \%$ more leaves than in control treatment, while shoot biomass in Ep+Eu was about twice higher than in both control and Ep treatments. In contrast, root biomass was significantly higher in the absence of Collembola and decreased in Ep or Eu treatments to reach a minimum in the Ep+Eu treatment. As a consequence, the shoot: root (S:R) ratio (Fig.

\section{Interaction between collembolan functional groups}

Results of two-way ANOVAs showed that the interaction between Ep and Eu (Ep x Eu) was significant for several plant variables (Foliar N, P, S content and plant height) and for soil ammonium concentration (Fig. 1 and Table 1). Furthermore, the Collembola Functional Group Effect index was statistically significant for 6 out of 9 variables tested (Table 2; Fig. 2), being consistent with previous results of the two-way ANOVAs. Observed Ep+Eu REI was significantly higher than the expected Ep+Eu REI for

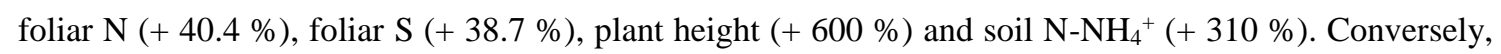
the observed Ep+Eu REI was significantly lower than the expected Ep+Eu REI for foliar P (-48.5\%) and root biomass $(-56.6 \%)$. 
Our results show that plant growth can be driven by the presence and composition of collembolan communities. In accordance with past observations (Scheu et al. 1999; Bardgett and Chan 1999; Cragg and Bardgett 2001; Forey et al. 2015) and our first hypothesis, the presence of Collembola in soil has a positive effect on plant morphological variables (i.e. number of leaves and shoot and root biomasses) and foliar nutrient contents. Although the presence of Collembola may affect plant performance in different ways (i.e. pathogen control or facilitation of plant-microbial assemblages), previous studies have shown that their main ecological role seems to increase nutrient availability for plants through stimulating mineralization processes (Gange 2000; Schütz et al. 2008; Eisenhauer et al. 2011; Forey et al. 2015). For instance, Scheu et al. (1999) and Bardgett and Chan (1999) showed that the presence of Collembola increases soil $\mathrm{N}$ mineralization. Likewise, Cragg and Bardgett (2001) reported a positive effect of collembolan species on soil processes such as litter degradation and $\mathrm{N}$ mineralization. Our finding appears to confirm this assumption, since we found higher concentrations of nutrients such as $\mathrm{N}$ in soil and plant in presence than in absence of Collembola.

Besides increase in nutrient availability, presence of Collembola can also enhance plant nutrient uptake by modifying the distribution of nutrients in the rhizosphere (Teuben 1991; Lussenhop 1992), increasing the formation of nutrient-rich patches and changing root morphological variables. As a consequence, plants tend to invest less in their roots when a soil is nutrient-rich (Hodge 2004, 2009; Endlweber et al. 2009). Those assumptions can explain the higher foliar nutrient contents and the lower root biomass observed in L. perenne growing with Collembola in the present study. Similar effects on root variables of collembolan presence were also previously documented (Partsch et al. 2006; Endlweber et al. 2009; Eisenhauer et al. 2011). Lambers et al. (2006) reported that $P$ acquisition could be increased by root traits like root proliferation or increased length of root hairs, enhancing allocation to shallow soil horizons, and mycorrhizal symbiosis. Although we only evaluated root biomass, we suggest that collembolan presence can modify root traits, for example by consuming vesicular-arbuscular mycorrhiza (VAM) hyphae which might negatively affect $\mathrm{P}$ uptake by roots, although this has not been conclusively demonstrated yet.

Previous studies have highlighted that soil processes and plant growth are strongly dependent on functional dissimilarity among soil fauna species (Heemsbergen et al. 2004; Eisenhauer et al. 2011). In the

294 present study, we expected that euedaphic and epedaphic communities differently influence plant 295 performence due to their different functional traits (Supplementary Table S1) and their different interactions 296 with soil microbes (Coulibaly et al. 2019). However, except for the number of L. perenne leaves, no 297 statistical difference was observed between both treatments, rejecting our second hypothesis: euedaphic 298 Collembola have not a more positive effect on plant growth than epedaphic species. Thus, different 299 functional groups of a same taxon (in this case, Collembola) might similarly affect plant growth, which 300 may reveal functional redundancy or a similar importance of both groups for plants. Surprisingly, the role played by these two collembolan functional groups on plant performance was little studied until now.

302 Eisenhauer et al. (2011) approached this by evaluating the effects of three collembolan species, each 303 belonging to a distinct functional group. They found that functional group effects depended on plant 304 functional group identity. Furthermore, it is well known that within the same functional group, species 
could differ regarding their functional traits and then their functions (Winck et al. 2017; Pey et al. 2014; Fonseca and Ganade 2001), altogether making predictions difficult. Determining and measuring effect traits of Collembola might partly solve the potential generalization of these results. However, we noted that euedaphic group tended to have a more positive effect on $L$. perenne performance compared with the epedaphic functional group, supporting the idea that euedaphic Collembola strongly interact with microbial communities in the rhizosphere, thereby increasing soil nutrients availability by stimulating microbial activity and mineralization (Petersen 2002).

Despite the potential functional redundancy between epedaphic and euedaphic Collembola revealed by the weak differences observed in terms of plant response to the presence of each functional group, the presence of both life-forms clearly showed significant interactions calling for functional complementarity (i.e. niche partitioning or facilitation; Hooper et al. 2005). Although our study did not evaluate the outcome of the interactions between collembolan species or functional groups on their own fitness, the overyielding observed in soil nutrients, foliar nutrients and in leaf numbers in the treatment including the two functional groups could be interpreted as a result of those interactions. We observed that the number of leaves and shoot biomass appear to be related to niche partitioning, while foliar nutrient content (N and $\mathrm{S}$ ) would result from facilitative interactions. Contrary to our results that did not reveal antagonisms between collembolan functional groups, Cragg and Bardgett (2001) found that an increase in collembolan species could reduce ecological processes in the soil due to competitive interaction among species. Furthermore, Eisenhauer et al. (2011) also showed that adding two collembolan species with similar functional traits could negatively affect plant performances due to strong competition between these species. We cannot exclude, and this is highly possible, that interspecific competitive interactions may have existed in our study. But those interactions have not prevailed between functional groups. This highlights the need when dealing with biotic interactions to consider as far as possible complex assemblages. The nature and magnitude of biotic interactions are fluctuating according to the biotic and abiotic environment (Bertness and Callaway 1994; Dangles et al. 2013; O'Brien et al. 2018).

The positive effect on plants and soil processes (i.e. overyielding) observed in the treatment combining both collembolan functional groups are supported by the study of Heemsbergen et al. (2004), as they found a positive linear response of leaf litter decomposition process to an increase in decomposer functional dissimilarity. Previous studies suggesting a distinct resource use and occupation of soil habitat

334 between these two collembolan functional groups can explain our findings (Gisin 1943; Petersen 2002;

335 Berg et al. 2004; Chahartaghi et al. 2005; Coulibaly et al. 2019). The overyielding effects observed in $L$.

336 perenne foliar nutrients appear to be related to an increase in mineralization processes leading to an increase 337 in nutrient availability and plant uptake. Similar results were reported by Eisenhauer et al. (2011), with an increase in collembolan species and functional richness leading to higher $\mathrm{C}$ and $\mathrm{N}$ mineralization and then increased leaf $\mathrm{N}$ content and shoot biomass of forbs. However, in a study focusing on the soil microbial compartment and associated functions, Coulibaly et al. (2019) pointed to a virtual lack of complementarity between epedaphic and euedaphic Collembola. Several studies have recently highlighted the role of signal molecules as an important feature of direct interactions between plants and free-living soil organisms, e.g. earthworms (Puga-Freitas and Blouin 2015). We could hypothesize that such direct interactions may exist

344 between Collembola and plants. Finally, although not documented in the literature, we cannot exclude that 
345 the presence of epedaphic Collembola may favor or facilitate euedaphic ones by fostering nutrient release

346 aboveground that could stimulate belowground microbial communities in the soil and thus provide more

347 resources for euedaphic Collembola.

\section{Conclusion}

We clearly demonstrated that a soil fauna group (here Collembola) might drive soil fertility and plant performances of a grass species (Lolium perenne) and that the magnitude and direction of these effects are strongly dependent on functional species assemblages. This experiment also highlights the importance of a diverse functional soil assemblage that might drive overyielding of ecological processes (among which plant productivity of an economically important forage species).

Experiments on ecosystem overyielding traditionally only manipulate specific and functional diversity of plants. Through our experimental approach, we demonstrated that manipulating soil functional assemblages at a local scale was experimentally possible, and was highly relevant for understanding synergistic effects on plant productivity. Thus, soil organism diversity-mediated interactions are essential for enhancing plant productivity and maximizing ecosystem processes and thus subsequent services. We strongly recommend developing such experimental methodology for different soil fauna group assemblages. Nevertheless, we recommend manipulating natural assemblages, considering the natural dissimilarity among species into every group regarding their functional traits. Lastly, our experiment also suggests positive interactions between collembolan functional groups. This experiment was not designed to study the nature of these interactions (competition vs. facilitation or complementarity), but similarly to plant-plant interaction theoretical models, we encourage to test direct and indirect positive interactions between Collembola and to test the importance of the environment on the intensity of these interactions.

\section{References}

Anderson MJ (2001) A new method for non-parametric multivariate analysis of variance. Austral Ecol 26:32-46. https://doi.org/10.1111/j.1442-9993.2001.tb00081.x

Bardgett RD, Chan KF (1999) Experimental evidence that soil fauna enhance nutrient mineralization and plant nutrient uptake in montane grassland ecosystems. Soil Biol Biochem 31:1007-1014. https://doi.org/10.1016/S0038-0717(99)00014-0

Berg MP, Stoffer M, Van Den Heuvel HH (2004) Feeding guilds in Collembola based on digestive enzymes. Pedobiologia 48:589-601. https://doi.org/10.1016/j.pedobi.2004.07.006

Bertness MD, Callaway R (1994) Positive interactions in communities. Trends Ecol Evol 9:187-191. https://doi.org/10.1016/0169-5347(94)90087-6 
Chahartaghi M, Langel R, Scheu S, Ruess L (2005) Feeding guilds in Collembola based on nitrogen stable isotope ratios. Soil Biol Biochem 37:1718-1725. https://doi.org/10.1016/j.soilbio.2005.02.006

Chauvat M, Perez G, Ponge J-F (2014) Foraging patterns of soil springtails are impacted by food resources. Appl Soil Ecol 82:72-77. https://doi.org/10.1016/j.apsoil.2014.05.012 Functional assemblages of Collembola determine soil microbial communities and associated functions. Front Environ Sci 7:52. https://doi.org/10.3389/fenvs.2019.00052

Cragg RG, Bardgett RD (2001) How changes in soil faunal diversity and composition within a trophic group influence decomposition processes. Soil Biol Biochem 33:2073-2081. https://doi.org/10.1016/S0038-0717(01)00138-9

Dangles O, Herrera M, Anthelme F (2013) Experimental support of the stress-gradient hypothesis in herbivore-herbivore interactions. New Phytol 197:405-408. https://doi.org/10.1111/nph.12080

Eisenhauer N, Hörsch V, Moeser J, Scheu S (2010) Synergistic effects of microbial and animal decomposers on plant and herbivore performance. Basic Appl Ecol 11:23-34. https://doi.org/10.1016/j.baae.2009.11.001

Eisenhauer N, Sabais ACW, Scheu S (2011) Collembola species composition and diversity effects on ecosystem functioning vary with plant functional group identity. Soil Biol Biochem 43:1697-1704. https://doi.org/10.1016/j.soilbio.2011.04.015

Eisenhauer N, Vogel A, Jensen B, Scheu S (2018) Decomposer diversity increases biomass production and shifts aboveground-belowground biomass allocation of common wheat. Sci Rep 8:17894. https://doi.org/10.1038/s41598-018-36294-3

Endlweber K, Ruess L, Scheu S (2009) Collembola switch diet in presence of plant roots thereby functioning as herbivores. Soil Biol Biochem 41:1151-1154. https://doi.org/10.1016/j.soilbio.2009.02.022

Finke DL, Snyder WE (2008) Niche Increases Resource Partitioning by Diverse Communities Exploitation. Science 321:1488-1490. https://doi.org/10.1126/science.1160854

Fonseca CR, Ganade G (2001) Species functional edundancy,random extinctions and the stability of ecosystems. J Ecol 89:118-125. https://doi.org/10.1046/j.1365-2745.2001.00528.x

Forey E, Coulibaly SFM, Chauvat M (2015) Flowering phenology of a herbaceous species (Poa annua) is regulated by soil Collembola. Soil Biol Biochem 90:30-33.

416 Gange A (2000) Arbuscular mycorrhizal fungi, Collembola and plant growth. Trends Ecol Evol 15:369- 

between functional groups of grasses. J Ecol 95:1296-1305. https://doi.org/10.1111/j.13652745.2007.01303.x

423 Guenay Y, Ebeling A, Steinauer K, et al (2013) Transgressive overyielding of soil microbial biomass in a grassland plant diversity gradient. Soil Biol Biochem 60:122-124. https://doi.org/10.1016/j.soilbio.2013.01.015

Hammer Ø, Harper DA., Ryan PD (2001) PAST: Paleontological statistics software package for education and data analysis. Palaeontol Electron 4:9

Hector A, Bazeley-White E, Loreau M, et al (2002) Overyielding in grassland communities: Testing the sampling effect hypothesis with replicated biodiversity experiments. Ecol Lett 5:502-511. https://doi.org/10.1046/j.1461-0248.2002.00337.x

Hedde M, Bureau F, Chauvat M, Decaëns T (2010) Patterns and mechanisms responsible for the relationship between the diversity of litter macro-invertebrates and leaf degradation. Basic Appl Ecol 11:35-44. https://doi.org/10.1016/j.baae.2009.10.009

Heemsbergen DA, Berg MP, Loreau M, et al (2004) Biodiversity Effects on Soil Processes Explained by Interspecific Functional Dissimilarity. Science 306:1019-1020. https://doi.org/10.1126/science.1101865

Hodge A (2004) The plastic plant: Root responses to heterogeneous supplies of nutrients. New Phytol 162:9-24. https://doi.org/10.1111/j.1469-8137.2004.01015.x

Hodge A (2009) Root decisions. Plant, Cell Environ 32:628-640. https://doi.org/10.1111/j.13653040.2008.01891.x

Hooper DU, Chapin FS, Ewel JJ., et al (2005) Effects of biodivesity on ecosystem functioning: a consensus of current knowledge. Ecol Monogr 1:3-35. https://doi.org/10.1890/04-0922

Hopkin SP (1997) Biology of the springtail (Insecta: Collembola). Oxford University Press

Lambers H, Shane MW, Cramer MD, et al (2006) Root structure and functioning for efficient acquisition of phosphorus: Matching morphological and physiological traits. Ann Bot 98:693-713. https://doi.org/10.1093/aob/mcl114

Lenoir L, Persson T, Bengtsson J, et al (2006) Bottom-up or top-down control in forest soil microcosms? Effects of soil fauna on fungal biomass and C/N mineralisation. Biol Fertil Soils 43:281-294. https://doi.org/10.1007/s00374-006-0103-8

Loreau M, Hector A (2001) Partitioning selection and complementarity in biodiversity experiments. Nature 412:72-76. https://doi.org/10.1038/35083573

Loreau M, Schmid B, Hector A, et al (2002) Overyielding in grassland communities: testing the sampling effect hypothesis with replicated biodiversity experiments. Ecol Lett 5:502-511. https://doi.org/10.1046/j.1461-0248.2002.00337.x

455 Lussenhop J (1992) Mechanisms of Microarthropod-Microbial Interactions in Soil. Elsevier 
Ngosong C, Raupp J, Richnow HH, et al (2004) Nitrogen isotope ratios and fatty acid composition as indicators of animal diets in belowground systems. Pedobiologia 139:2308-2317. https://doi.org/10.1007/s00442-004-1514-6

O’Brien AM, Sawers RJH, Ross-Ibarra J, Strauss SY (2018) Extending the Stress-Gradient hypothesis: greater adaptation between teosinte and soil biota at higher stress sites. Am Nat 192:715-730. https://doi.org/10.1086/700118

Partsch S, Milcu A, Scheu S (2006) Decomposers (Lumbricidae, Collembola) Affect Plant Performance in Model Grasslands of Different Diversity. Ecology 87:2548-2558. https://doi.org/10.1890/00129658

Petersen H (2002) General aspects of collembolan ecology at the turn of the millennium. Pedobiologia 46:246-260. https://doi.org/10.1078/0031-4056-00131

Pey B, Nahmani J, Auclerc A, et al (2014) Current use of and future needs for soil invertebrate functional traits in community ecology. Basic Appl Ecol 15:194-206. https://doi.org/10.1016/j.baae.2014.03.007

Puga-Freitas R, Blouin M (2015) A review of the effects of soil organisms on plant hormone signalling pathways. Environ Exp Bot 14:104-116. https://doi.org/10.1016/j.envexpbot.2014.07.006

Rusek J (1998) Development and progress in Apterygota research in the territory of the former Czechoslovakia. Pedobiologia 46:201-208. https://doi.org/10.1016/S0031-4056(04)70135-3

Santonja M, Baldy V, Fernandez C, Balesdent J, Gauquelin T (2015) Potential shift in plant communities with climate change in a Mediterranean Oak forest: consequence on nutrients and secondary metabolites release during litter decomposition. Ecosystems 18:1253-1268. https://doi.org/10.1007/s10021-015-9896-3

Scheu S, Theenhaus A, Jones TH (1999) Links between the detritivore and the herbivore system: Effects of earthworms and Collembola on plant growth and aphid development. Oecologia 119:541-551. https://doi.org/10.1007/s004420050817

Schmid B, Hector A, Saha P, Loreau M (2008) Biodiversity effects and transgressive overyielding. J Plant Ecol 1:95-102. https://doi.org/10.1093/jpe/rtn011

Schütz K, Bonkowski M, Scheu S (2008) Effects of Collembola and fertilizers on plant performance (Triticum aestivum) and aphid reproduction (Rhopalosiphum padi). Basic Appl Ecol 9:182-188. https://doi.org/10.1016/j.baae.2006.07.003

Teuben A (1991) Nutrient availability and interactions between soil arthropods and microorganisms during decomposition of coniferous litter: a mesocosm study. Biol Fertil Soils 10:256-266. https://doi.org/10.1007/BF00337376

Tordoff GM, Boddy L, Jones TH (2008) Species-specific impacts of collembola grazing on fungal foraging ecology. Soil Biol Biochem 40:434-442. https://doi.org/10.1016/j.soilbio.2007.09.006

Wagg C, Bender SF, Widmer F, van der Heijden MGA (2014) Soil biodiversity and soil community 

https://doi.org/10.1073/pnas.1320054111

494 Winck BR, Saccol de Sá EL, Rigotti VM, Chauvat M (2017) Relationship between land-use types and 495 functional diversity of epigeic Collembola in Southern Brazil. Appl Soil Ecol 109:49-59. https://doi.org/10.1016/j.apsoil.2016.09.021

497 

groups. Means $\pm \mathrm{SD}$

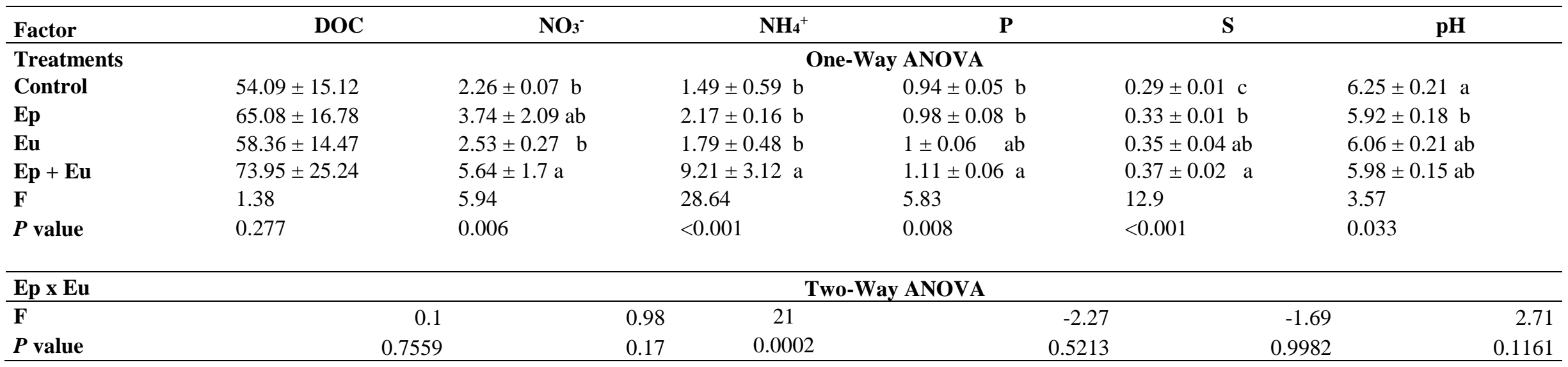

${ }^{1}$ The $\mathrm{P}$ value in bold indicates a significant effect $(\mathrm{P}<0.05)$ of collembolan life form on the plant variables using analysis of variance (ANOVA One-Way) with permutation tests. P value was calculated with 9999 permutations. Different letters denote significant differences between means at the 5\% level variables according to One-way ANOVA with the factor "treatment". Partial results (interactive terms between factors) of Two-way ANOVA (with Ep and Eu as factors) are also given. P value was calculated with 5069999 permutations 
507 Table 2. Complementary effect of Observed and Expected Ep+Eu values for soil and plant variables were

508 calculated using the Relative Effect Index (REI) and compared with a $t$ test. Combined Functional Group

509 Effect (CFGE) was calculated according to the formula: Observed REI - Expected REI. Null CFGE =

510 simple additive effect, indicating niche partitioning; positive CFGE = overyielding, and negative CFGE=

511 underyielding. For more details, see the material and method section. Ep= epedaphic Collembola, Eu= 512 euedaphic Collembola.

513

\begin{tabular}{|c|c|c|c|c|c|}
\hline \multirow[t]{2}{*}{ Variables } & Observed REI & Expected REI & $t$ test & \multirow[t]{2}{*}{$P$ value } & \multirow[t]{2}{*}{ CFGE } \\
\hline & $\mathrm{Ep}+\mathrm{Eu}$ & $\mathrm{Ep}+\mathrm{Eu}$ & & & \\
\hline \multicolumn{6}{|c|}{ Plant variables } \\
\hline Foliar C & -0.05 & -0.02 & 1.75 & 0.101 & $\mathbf{0}$ \\
\hline Foliar N & 0.66 & 0.47 & -2.41 & 0.03 & + \\
\hline Foliar P & -0.33 & -0.49 & -2.67 & 0.032 & - \\
\hline Foliar S & 1.21 & 0.80 & -3.45 & 0.011 & + \\
\hline Plant height & -0.03 & -0.21 & -3.07 & 0.006 & + \\
\hline Number of leaves & 0.72 & 0.56 & -1.28 & 0.228 & $\mathbf{0}$ \\
\hline Shoot biomass & 1.39 & 0.50 & -1.06 & 0.33 & $\mathbf{0}$ \\
\hline Root biomass & -0.83 & -1.30 & -8.02 & 0.009 & - \\
\hline SR ratio & 6.06 & 3.78 & -1.87 & 0.008 & + \\
\hline \multicolumn{6}{|c|}{ Soil variables } \\
\hline $\mathrm{N}-\mathrm{NO}_{3}{ }^{-}$ & 1.50 & 0.78 & -1.29 & 0.233 & $\mathbf{0}$ \\
\hline $\mathrm{N}-\mathrm{NH}_{4}^{-}$ & 5.42 & 1.32 & -3.32 & 0.011 & + \\
\hline Phosphorus & 0.18 & 0.11 & -1.33 & 0.225 & $\mathbf{0}$ \\
\hline Sulfur & 0.26 & 0.30 & 1.49 & 0.171 & $\mathbf{0}$ \\
\hline
\end{tabular}

514 

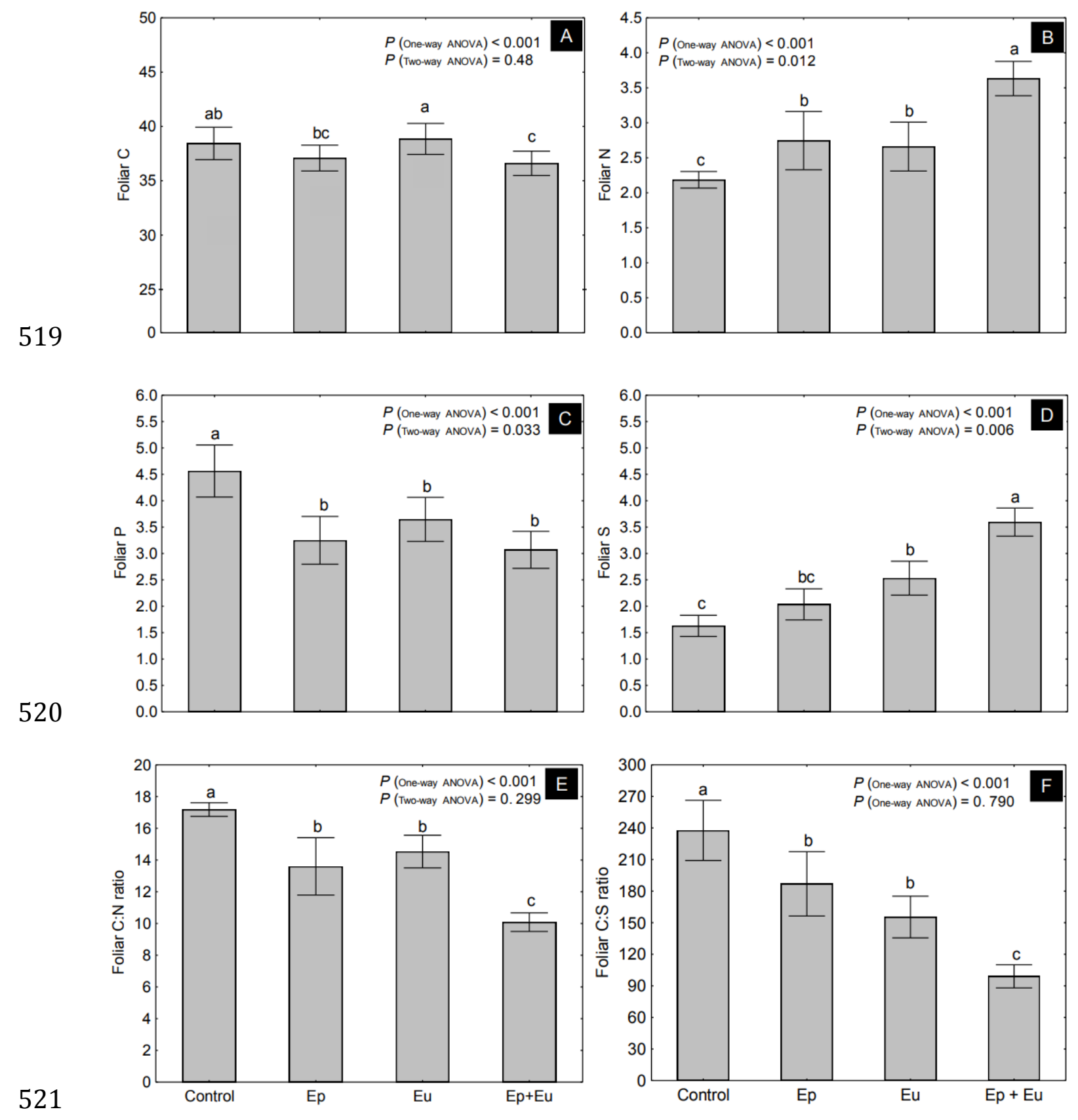

522 

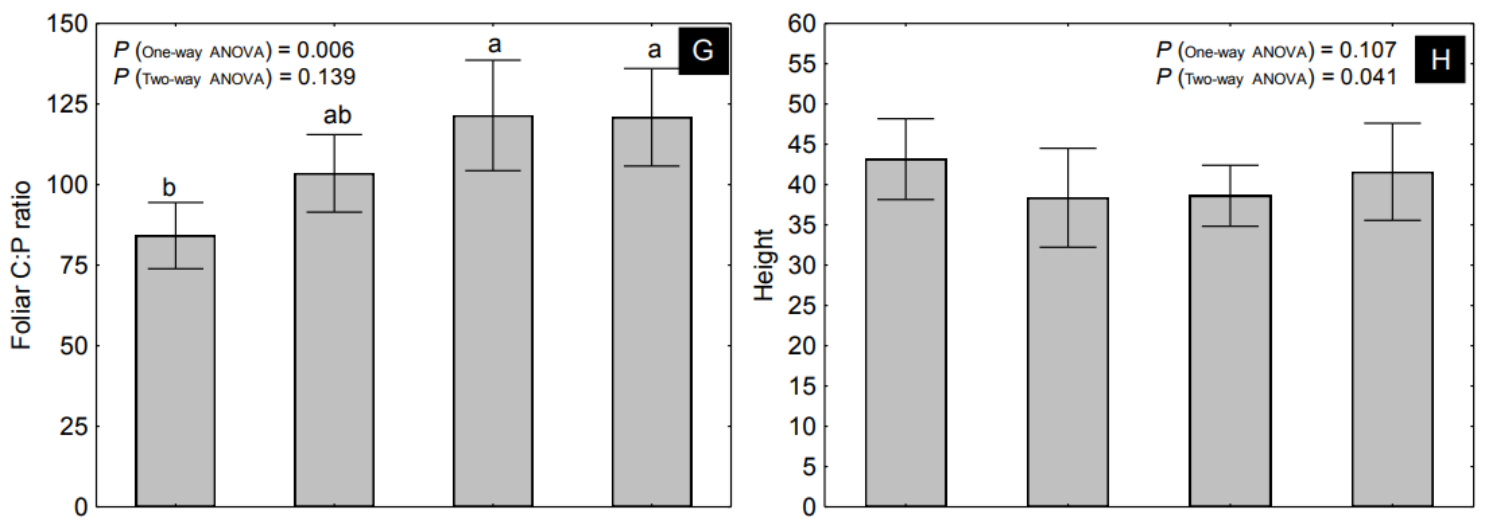

524
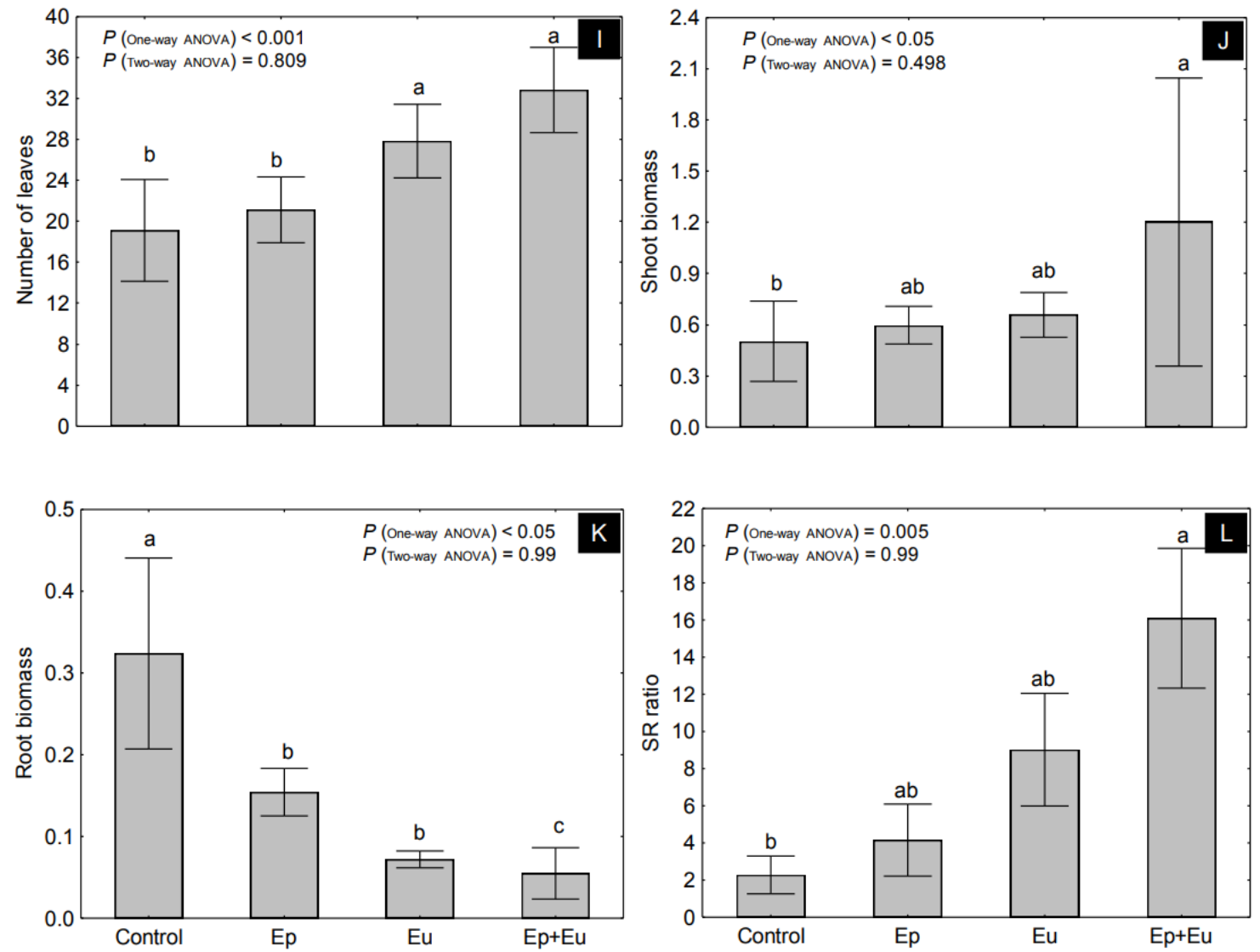

526 Figure 1. Attributes of Lolium perenne according to four different treatments corresponding to the presence or not of different functional groups of Collembola. Control: without Collembola; Eu: euedaphic

528 Collembola; Ep: epedaphic Collembola; Ep + Eu: combined functional groups. Error bars show standard error. Different letters denote significant differences between means at the $5 \%$ level variables according to

530 One-way ANOVA with the factor "treatment". Partial results (interactive terms between factors) of Twoway ANOVA (with Ep and Eu as factors) are also given. $P$ value was calculated with 9999 permutations. 

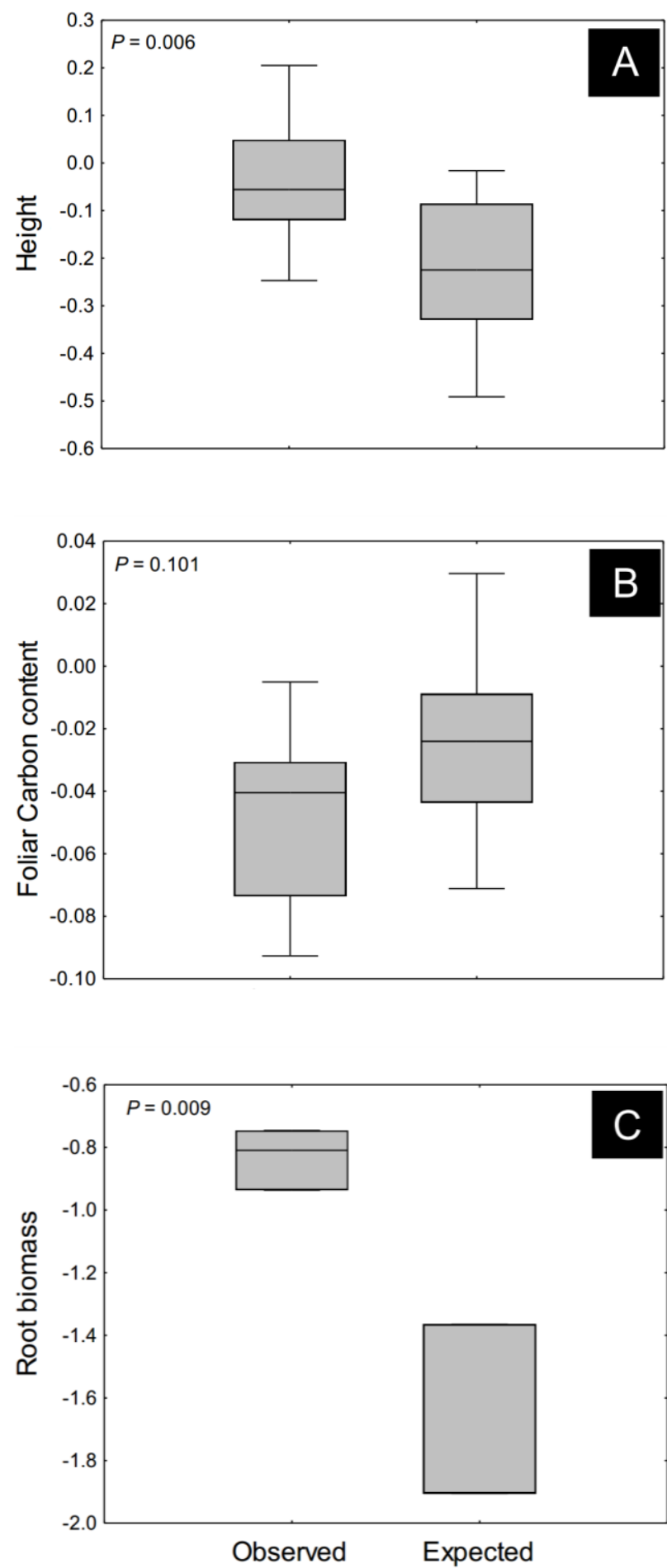

535

536 Relative Effect Index of height (A), foliar carbon content (B) and root biomass (C) of Lolium 536

537 perenne in observed and expected combination of collembolan functional groups (Ep+Eu). Eu: euedaphic

538 Collembola; Ep: epedaphic Collembola; Ep + Eu: Error bars show standard error. $P$ value was calculated 539 with 9999 permutations. 
543 Functional groups of Collembola induce different plant responses in Lolium perenne.

544

545 Bruna R. Winck ${ }^{1^{*}+}$, Matthieu Chauvat ${ }^{2 *+}$, Sekou F.M. Coulibaly ${ }^{2 *}$, Mathieu Santonja ${ }^{3}$, Enilson Luiz Saccol 546 de Sá ${ }^{4}$, Estelle Forey ${ }^{2 *}$

547

$548{ }^{1}$ Department of Ecology, Federal University of Rio Grande do Sul-UFRGS, 91501-970, Porto Alegre 549 RS, Brazil. ${ }^{(+)}$Email: bru.winck@ gmail.com

550

$5512{ }^{2}$ Normandie Université, UNIROUEN, IRSTEA, ECODIV, FED SCALE CNRS 3730, France. ${ }^{(+)}$Email: 552 matthieu.chauvat@univ-rouen.fr.

553

$554{ }^{3}$ Aix Marseille Univ, Avignon Université, CNRS, IRD, IMBE, Marseille, France

555

$556{ }^{4}$ Department of Soil Science, Federal University of Rio Grande do Sul-UFRGS, 91540-000, Porto Alegre 557 - RS, Brazil

558

$559 *$ These authors contributed equally to the work

560

561 
Table S1: Assemblages of Collembola at the start and the end of the experiment (i.e. 5 months later) in 3 different treatments (Ep, Eu and Ep+Eu). Mean (and SD) abundances per species are given $(\mathrm{n}=5)$. Total mean abundance (SD), mean biomass of $\mathrm{C}$ and $\mathrm{N}$ content of the Collembola 565 are given per treatment. $\mathrm{EP}=$ epedaphic species, $\mathrm{EU}=$ euedaphic species.

566

\begin{tabular}{lllllll}
\hline Species & \multicolumn{3}{c}{ START (T=0) } & \multicolumn{3}{c}{ END (T=5 months) } \\
& $\mathrm{Ep}$ & $\mathrm{Eu}$ & $\mathrm{Ep}+\mathrm{Eu}$ & $\mathrm{Ep}$ & $\mathrm{Eu}$ & \multicolumn{2}{c}{$\mathrm{Ep}+\mathrm{Eu}$} \\
\hline Isotomurus prasinus & $5.0(5.0)$ & $0.4(0.9)$ & $4.4(3.8)$ & $3.0(1.4)$ & $0.0(0)$ & $3(3.7)$ \\
Lepidocyrtus cyaneus & $2.8(1.6)$ & $0.2(0.4)$ & $1.6(1.1)$ & $4.2(3.0)$ & $0.2(0.5)$ & $3.8(2.3)$ \\
Desoria violacea & $1.2(1.3)$ & $0.0(0)$ & $0.8(1.1)$ & $1.8(0.8)$ & $0.2(0.5)$ & $1.2(1.3)$ \\
Stenacidia violacea & $0.2(0.4)$ & $0.0(0)$ & $0.0(0)$ & $0.6(0.5)$ & $0.0(0)$ & $0.4(0.5)$ \\
Cryptopygus thermophilus & $0.2(0.4)$ & $2.2(1.9)$ & $2.8(2.6)$ & $0.0(0)$ & $3.8(2.6)$ & $3.2(2.8)$ \\
Isotomiella minor & $0.0(0)$ & $7.2(3.1)$ & $7.0(3.3)$ & $0.0(0)$ & $11.4(5.9)$ & $14.4(9.8)$ \\
Paratullbergia callipygos & $0.0(0)$ & $1.4(1.3)$ & $2.4(3.6)$ & $0.0(0)$ & $1.8(0.5)$ & $0.4(0.5)$ \\
Protaphorura armata gr & $0.0(0)$ & $1.8(0.8)$ & $2.2(1.5)$ & $0.0(0)$ & $3.4(3.0)$ & $6.4(4.2)$ \\
Mesophorura yosii & $0.0(0)$ & $6.6(5.5)$ & $6.0(4.5)$ & $0.0(0)$ & $10.0(7.1)$ & $11.8(6.0)$ \\
Dicyrtoma fusca & $0.0(0)$ & $0.0(0)$ & $0.0(0)$ & $0.0(0)$ & $0.0(0)$ & $0.2(0.4)$ \\
Total abundance & $9.4(6.5)$ & $19.8(5.1)$ & $27.2(5.5)$ & $9.6(1.1)$ & $30.8(8.1)$ & $44.8(16.8)$ \\
Biomass C $(\mu \mathrm{g} \mathrm{C})$ & 195.3 & 51.4 & 204.9 & 143.4 & 63.6 & 223.4 \\
Biomass N $(\mu \mathrm{g} \mathrm{N})$ & 38.0 & 10.3 & 40.3 & 28.7 & 12.7 & 44.7 \\
\hline
\end{tabular}

